\title{
The effects of a community-based walking program on walking ability and fall-related self-efficacy of chronic stroke patients
}

\author{
Jun-Min Lee' ${ }^{1}$ Hyung-Hoon Moon², Sung-Ki Lee², Hae-Lim Lee ${ }^{3}$, Yun-Jin Park ${ }^{3, *}$ \\ ${ }^{1}$ National Rehabilitation Center, Seoul, Korea \\ 2Department of Sports Medicine, College of Health Sciences, CHA University, Pocheon, Korea \\ ${ }^{3}$ School of Global Sport Studies, Korea University, Sejong, Korea
}

The objectives of this study were to evaluate the effects of community-based walking training (CWT) on the walking ability and fall-related self-efficacy of chronic stroke patients and compare the effects of CWT to the conventional walking programs in stroke patients. Previous studies focused on walking speed, walking endurance, and balance. However, no studies have examined the changes in fall-related self-efficacy after CWT. In order to achieve purpose of this study, 45 chronic stroke patients, who were hospitalized at National Rehabilitation Center, were randomly divided into the CWT group (CWTG, $n=15$ ), the treadmill walking training group (TWTG, $n=15$ ), and the control group (CG, $n=15$ ). The treatment was conducted 3 times per week ( 30 min each) for 4 weeks. CWT was carried out by gradually increasing the difficulty level in vari- ous environments outside the hospital room. The results revealed that the CWTG was more effective in enhancing the walking ability and fall-related self-efficacy than the TWTG and the CG. These findings demonstrated that the CWTG increased the walking ability and fall-related self-efficacy of chronic stroke patients. Therefore, we suggest that adding CWT to standard rehabilitation might be an effective method for improving walking ability and fall-related self-efficacy in chronic stroke patients.

Keywords: Walking speed, Walking endurance, Dynamic balance, Walking ability, Fall-related self-efficacy

\section{INTRODUCTION}

The reacquisition of independent gait ability is the primary goal of stroke patients in order to achieve independent living and social activities. Therefore, it is an important topic of the physical therapy (Dunsky et al., 2008). However, there are many difficulties in reacquiring independent gait after stroke due to the neurological disorder of the body and the psychological fear of falling (Fletcher and Hirdes, 2004; Fritz et al., 2007). Representative gait trainings for stroke patients in clinical practice include treadmill walking training (Lindquist et al., 2007), task-oriented circuit training (Chisari et al., 2014), imagery training (Braun et al., 2006), gait training in various obstacle courses (Dean et al., 2000), and virtual reality programs (Lord et al., 2004). However, these exercises are only available to the stable indoor environment and do not take into account the various environmental factors, which are required for patients to participate in community activities (Lord and Rochester, 2005). Consequently, to supplement these shortfalls, the gait training for stroke patients has been extended to community ambulation, which is an integration of mobility and social activities (Lord et al., 2004). Community ambulation refers to an individual's ability to walk in a public place and in various environments (e.g., crossing a crosswalk, walking on a ramp, and avoiding an obstacle) satisfactorily (Lord et al., 2004). Community ambulation requires independent gait, proper walking speed and endurance, and dynamic balance ability in addition to integrated cognitive control capabilities to avoid obstacles or change direction (Courtine and Schieppati, 2003).
${ }^{*}$ Corresponding author: Yun-Jin Park (iD https://orcid.org/0000-0001-6696-2542 School of Global Sport Studies, Korea University, 2511 Sejong-ro, Jochiwon-eup, Sejong 30019, Korea

E-mail: africca3535@gmail.com

Received: October 12, 2018 / Accepted: December 31, 2018
This is an Open Access article distributed under the terms of the Creative Commons Attribution Non-Commercial License (http://creativecommons.org/licenses/by-nc/4.0/) which permits unrestricted non-commercial use, distribution, and reproduction in any medium, provided the original work is properly cited. 
However, many stroke patients have not been able to conduct lifestyle activities at full scale and only $7.3 \%$ of them were able to walk around the community successfully (Lord et al., 2004). Therefore, recent studies on the community-based walking program (CWP) have reported that the CWP could help stroke patients conduct independent external activities (Salbach et al., 2004; Stuart et al., 2009). Moreover, these studies have shown the CWP improved the walking speed and endurance, balance ability, and stroke impact scale of stroke patients (Stuart et al., 2009). However, the CWP used in these studies only consisted of a low walking speed (mean after the experiment: $0.49-0.51 \mathrm{~m} / \mathrm{sec}$ ) and a short walking distance (mean: 114.14-162.59 m) and the participants of these studies had good balance ability. Additionally, although the walking speed and walking distance of the patients improved to $0.63-0.7 \mathrm{~m} / \mathrm{sec}$ and $183.93-227.80 \mathrm{~m}$, respectively, they did not reach the threshold for participating in community activities (walking speed $>0.8 / \mathrm{sec}$ and walking distance $>300 \mathrm{~m}$ ) (Perry et al., 1995).

Therefore, generalizing the results of these studies is challenging. Additionally, it is not known how a CWP affects the social participation and psychological efficacy of these participants. The objective of this study was to evaluate the effects of a CWP on the walking ability, and those of fall-related self-efficacy on chronic stroke patients.

\section{MATERIALS AND METHODS}

\section{Subjects}

This study examined 45 chronic stroke patients who were admitted to the National Rehabilitation Center in Seoul. The subjects selected for the study understood the objective of the study and consented to participate in the study. They were chronic stroke patients and had their last strokes more than 3 months pre- viously. They also could walk more than $10 \mathrm{~m}$ without using an assistance device. Each subject had a Korean Mini-Mental State Examination (MMSE-K) score equal to or higher than 24. This study excluded patients who had other neurological and orthopedic problems other than cerebral infarction, audiovisual impairments including unilateral neglect, composite spasticity score of ankle plantarflexor equal to or higher than 10 (Levin and HuiChan, 1992), and an ankle dorsiflexor at passive motion equal to or lower than $10^{\circ}$ (Table 1). Pearson chi-square test (sex, the cause of illness, and paralyzed side) and the Scheffe test (age, duration of disease, MMSE-K, and FAC) were conducted to verify the homogeneity of the intergroup variables according to the general characteristics of the study subjects. The general characteristics and homogeneity of the subjects are presented in Table 1.

\section{Study design}

Forty-five stroke patients were randomly grouped into the CWP group (CWTG), treadmill walking training group (TWTG), and control group (CG) and each group had 15 patients. In addition to the treatment, all subjects received physical therapy for $30 \mathrm{~min}$ per day, 5 times a week, for 4 weeks. The CWTG and the TWTG performed walking training for 4 weeks (three sessions per week and 30 min per session) and the CG only received general physical therapy. A pre-evaluation was carried out by performing a $10-\mathrm{m}$ walk test (walking speed), a 6-min walk assessment (walking endurance), and a Timed Up \& Go Test (TUGT, dynamic balance), and fall-related self-efficacy on the day before the experiment commenced. The same tests were conducted 4 weeks later as a postevaluation.

\section{Community-based walking program}

The CWP contains a variety of community walking programs, including flat indoor and outdoor walking, up and down stairs,

Table 1. Physical characteristics of subjects

\begin{tabular}{|c|c|c|c|c|c|}
\hline Characteristic & CWTG & TWTG & CG & $\chi^{2} / F$ & $P$-value \\
\hline Age (yr) & $50.40 \pm 9.30$ & $53.20 \pm 9.77$ & $53.80 \pm 12.15$ & - & - \\
\hline Gender, male:female & 11:4 & $12: 3$ & $10: 5$ & 0.682 & 0.711 \\
\hline Time since onset (yr) & $8.47 \pm 4.26$ & $7.80 \pm 2.68$ & $6.67 \pm 2.61$ & 1.161 & 0.323 \\
\hline MMSE-K & $29.13 \pm 1.19$ & $29.53 \pm 1.13$ & $28.87 \pm 1.69$ & 0.919 & 0.407 \\
\hline FAC & $4.07 \pm 0.26$ & $4.20 \pm 0.14$ & $4.00 \pm 0.54$ & 0.891 & 0.418 \\
\hline Cause of occurrence, infarction:hemorrhage & $8: 7$ & $6: 9$ & $9: 6$ & 1.245 & 0.537 \\
\hline Affected side, right:left & $7: 8$ & $7: 8$ & $11: 4$ & 2.880 & 0.237 \\
\hline
\end{tabular}

Values are presented as mean \pm standard deviation or number.

CWTG, community-based walking program group; TWTG, treadmill walking training group; CG, control group; MMSE-K, mini-mental state examination-Korean; FAC, functional ambulation classification. 
ramps, uneven areas, and pedestrian crossings, and gradually increases the intensity of exercise as proposed by Shumway-Cook et al. (2002). In the first week, subjects trained to walk $150 \mathrm{~m}$ including in an indoor corridor, up hospital stairs, and on an indoor slope. In the second week, subjects trained to walk 200 m including outdoor obstacle avoidance training. In the third week, subjects trained to walk $300 \mathrm{~m}$ including the hospital crosswalk (width $=4.3 \mathrm{~m}$ and length $=8 \mathrm{~m}$ ), walking up and down a slope, and avoiding obstacles. In the fourth week, subjects were instructed to walk $500 \mathrm{~m}$, including crossing the crosswalks in the community (width $=3.4 \mathrm{~m}$ and length $=16 \mathrm{~m}$ ), walking to the hospital lobby through an indoor parking lot with heavy traffic and stairs, walking outdoors while carrying an object, and while pushing a cart.

\section{Treadmill walking program}

Subjects of the TWTG performed stretches of the lower limbs (10 $\mathrm{min}$ ) as a warm-up before exercise. Subjects started their treadmill walks at the initial speed range of $0.25-0.40 \mathrm{~m} / \mathrm{sec}$ and they increased the speed by $5 \%$ per week for 4 weeks according to their gait ability. This increase in speed did not diminish the independence or stability of the subjects. When a subject could not secure stability after increasing the speed, the subject conducted the training at the speed of the previous training level (Pohl et al., 2002).

\section{Physical therapy}

Traditional walking exercise, neurodevelopmental treatment, and proprioceptive neuromuscular facilitation were performed in accordance with the prescriptions of the rehabilitation physicians.

\section{Data analysis}

This study used IBM SPSS Statistics ver. 21.0 (IBM Co., Armonk, NY, USA) for statistical analysis. A chi-square test and a one-way analysis of variance (ANOVA) were conducted with the Scheff post hoc test to compare the variables among the three groups $(P<0.05)$. The characteristics of the subjects were analyzed by carrying out frequency analysis and descriptive statistics. A one-way ANOVA was performed to evaluate the effects of the exercise method and measurement period. Moreover, a paired $t$-test was conducted to examine the effects of treatments within each group.

\section{RESULTS}

\section{Changes in walking ability by training methods Walking speed}

The walking speed significantly $(P<0.01)$ increased after treatments in the CWTG, TWTG, and CG (Table 2). The walking speed of CWTG was significantly different from that of the TWTG and that of the CG $(P<0.01)$. The results of the post boc

Table 2. Change of walking ability, fall-related self-efficacy, and community participation

\begin{tabular}{|c|c|c|c|c|c|c|}
\hline Measure & CWTG $^{\text {a) }}(n=15)$ & TWTG $^{\text {b) }}(n=15)$ & $C G^{c)}(n=15)$ & $F$ & $P$-value & Posthoc \\
\hline Walking speed (m/sec) & & & & 22.099 & $0.001^{\dagger \dagger}$ & $a>b, c$ \\
\hline Pretest & $0.63 \pm 0.16$ & $0.66 \pm 0.22$ & $0.62 \pm 0.14$ & & & \\
\hline Posttest & $0.83 \pm 0.12^{* *}$ & $0.78 \pm 0.19^{* *}$ & $0.65 \pm 0.13^{*}$ & & & \\
\hline Walking distance (m) & & & & 28.050 & $0.001^{\dagger \dagger}$ & $a>b, c$ \\
\hline Pretest & $243.87 \pm 61.22$ & $256.51 \pm 82.86$ & $226.38 \pm 50.50$ & & & \\
\hline Posttest & $311.18 \pm 46.59^{* *}$ & $293.05 \pm 73.40^{* *}$ & $234.96 \pm 51.06$ & & & \\
\hline Dynamic balance ability (sec) & & & & 19.141 & $0.001^{\dagger \dagger}$ & $a, b>c$ \\
\hline Pretest & $17.93 \pm 5.32$ & $2.53 \pm 0.51$ & $2.87 \pm 0.74$ & & & \\
\hline Posttest & $14.27 \pm 3.52^{* *}$ & $2.00 \pm 0.54^{* *}$ & $2.67 \pm 0.49$ & & & \\
\hline Fall-related self-efficacy (point) & & & & 33.552 & $0.001^{\dagger \dagger}$ & $a>b, c$ \\
\hline Pretest & $72.13 \pm 38.50$ & $82.80 \pm 37.29$ & $63.93 \pm 39.48$ & & & \\
\hline Posttest & $116.93 \pm 17.68^{* *}$ & $94.13 \pm 32.13^{* *}$ & $69.06 \pm 37.91^{* *}$ & & & \\
\hline Community participation (point) & & & & 19.141 & $0.001^{t \dagger}$ & $a>b, c$ \\
\hline Pretest & $2.53 \pm 0.64$ & $2.53 \pm 0.51$ & $2.89 \pm 0.74$ & & & \\
\hline Posttest & $1.33 \pm 0.49$ & $2.00 \pm 0.54$ & $2.67 \pm 0.49$ & & & \\
\hline
\end{tabular}

Values are presented as mean \pm standard deviation.

CWTG, community-based walking program group; TWTG, treadmill walking training group; CG, control group.

${ }^{*} P<0.05,{ }^{* *} P<0.01$ in significant differences within paired $t$-test. ${ }^{t t} P<0.01$ in significant differences using one-way analysis of variance. 
analysis indicated that the walking speed of the CWTG was significantly higher than that of the TWTG and that of the CG.

\section{Walking endurance}

The walking endurance significantly $(P<0.01)$ increased after treatments in the CWTG and the TWTG (Table 2). However, the treatment showed no significantly $(P<0.05)$ effect in the CG (Table 2). The walking endurance of the CWTG was significantly higher than that of the TWTG and that of the CG $(P<0.01)$.

\section{Dynamic balance ability}

The dynamic balance ability significantly $(P<0.01)$ decreased after treatments in the CWTG and the TWTG (Table 2). However, it did not change significantly $(P<0.05)$ in the $C G$ after the treatment (Table 2). The dynamic balance ability of CWTG was significantly higher than that of the TWTG and that of the CG $(P<$ 0.01). The results of the post boc analysis also revealed that the dynamic balance ability of the CWTG and that of the TWPG were significantly $(P<0.05)$ different from that of the CG (Table 2$)$.

\section{Changes in fall-related self-efficacy by training methods}

The fall-related self-efficacy significantly $(P<0.01)$ increased after treatments in the CWTG, the TWTG, and the CG. The fall-related self-efficacy of the CWTG was significantly different from that of the TWTG and that of the CG $(P<0.01)$.

\section{DISCUSSION}

This study used the 6-min gait evaluation which tests walking speed and walking endurance. This is the standard method for predicting the community gait level of stroke patients (Lord et al., 2004). The results of this study showed that the CWTG significantly increased the walking speed. Moreover, it was also found that the CWTG had significantly higher walking endurance than the TWTG and the CG. The results implied that the CWTG was the most helpful to increase walking speed and walking endurance among these treatments. The CWP could be the most effective because it is a task-oriented training and it asks a subject to complete various tasks within a given time (Courtine and Schieppati, 2003).

The walking speed required for a pedestrian to walk in a community is $0.8-1.2 \mathrm{~m} / \mathrm{sec}$ (Bijleveld-Uitman et al., 2013). The walking speed of subjects in this study was within this range. Generally, the 6-min gait test of a healthy adult is $500-700 \mathrm{~m}$ on average, and the minimum walking endurance required for stroke patients to walk in a community is between 300 and $500 \mathrm{~m}$ (Bijleveld-Uitman et al., 2013). The results of similar previous studies (Stuart et al., 2009) showed that CWP significantly increased walking distance, which supports the results of this study. However, the gait performance of the subjects of these previous studies did not meet the community gait standard (Perry et al., 1995).

This study also used a TUGT, which is another evaluation method of gait level, to evaluate the dynamic balance ability of patients. The results of this study showed that the CWTG increased the TUGT significantly more than the TWTG and the CG. The TUGT is a task requiring complex exercises and it is composed of various posture control and continuous exercise tasks, such as straight walking, curved walking, and changing direction walking (Hess et al., 2010). This study conducted walking training with increasing the environmental requirement proposed by Shumway-Cook et al. (2002) weekly. Subjects had to carry out tasks in a complex environment such as avoiding obstacles (e.g., cars and pedestrians) while increasing the slope weekly. It is believed that it is why the CWTG had better performance more than the other groups. The difficulty of independent walking after a stroke, the dependent living environment, and the persistent functional impairment increase the psychological fear of stroke patients (Harris et al., 2005). Particularly, Schmid et al. (2012) reported that most of the stroke patients who experienced multiple fall incidents had a low quality of life. Moreover, Andersson et al. (2008) revealed that, regardless of a fall incident experience, a group with a higher fall-related self-efficacy had better exercise functions of upper and lower limbs in the paralyzed side, a higher TUGT result, and a higher Berg Balance Scale score than a group with a lower fall-related self-efficacy. Furthermore, Andersson et al. (2008) showed that there was a significant difference in the Geriatric Depression Scale, a psychological factor, between the two groups.

However, MMSE results were not significantly different between the two groups. This study evaluated how a CWP for stroke patients affected the fall-related self-efficacy. The results of this study showed that the CWP could improve the fall-related self-efficacy significantly better than the TWT and no treatment (CG). The CWP showed the highest changes in this study, more than treadmill walking training and general physical therapy. This was because other therapies were repetitive and focused on limited areas without considering dynamic factors in a community. The results of this study suggested that it would be necessary to adopt a CWP, which is effective in reducing the psychological fear of falls and increasing the fall-related self-efficacy of stroke patients. 
The well-planned CWT program, which takes into account environmental challenges, seems to have better results in community walking owing to higher self-confidence and better mobility. The CWP is composed of the tasks required in the actual community walking and it implements the elements of the program in a cyclic fashion. The program would promote the quality of life by introducing diverse walking training tasks. Moreover, it is more effective than other training programs conducted under limited environmental conditions since it increases the range of physical activities by introducing various opportunities of experience, inducing motivation and interest in therapy, and reducing stress. Future studies are needed to add diverse elements to the CWP in order to improve the quality of life of stroke patients with different disabilities.

\section{CONFLICT OF INTEREST}

No potential conflict of interest relevant to this article was reported.

\section{ACKNOWLEDGMENTS}

This work was supported by the National Rehabilitation Center Research Ethics Review Committee (NRC-2017-02-014).

\section{REFERENCES}

Andersson AG, Kamwendo K, Appelros P. Fear of falling in stroke patients: relationship with previous falls and functional characteristics. Int J Rehabil Res 2008;31:261-264.

Bijleveld-Uitman M, van de Port I, Kwakkel G. Is gait speed or walking distance a better predictor for community walking after stroke? J Rehabil Med 2013;45:535-540.

Braun SM, Beurskens AJ, Borm PJ, Schack T, Wade DT. The effects of mental practice in stroke rehabilitation: a systematic review. Arch Phys Med Rehabil 2006;87:842-852.

Chisari C, Venturi M, Bertolucci F, Fanciullacci C, Rossi B. Benefits of an intensive task-oriented circuit training in Multiple Sclerosis patients with mild disability. NeuroRehabilitation 2014;35:509-518

Courtine G, Schieppati M. Human walking along a curved path. I. Body trajectory, segment orientation and the effect of vision. Eur J Neurosci 2003;18:177-190

Dean CM, Richards CL, Malouin F. Task-related circuit training improves performance of locomotor tasks in chronic stroke: a randomized, controlled pilot trial. Arch Phys Med Rehabil 2000;81:409-417.
Dunsky A, Dickstein R, Marcovitz E, Levy S, Deutsch JE. Home-based motor imagery training for gait rehabilitation of people with chronic poststroke hemiparesis. Arch Phys Med Rehabil 2008;89:1580-1588.

Fletcher PC, Hirdes JP. Restriction in activity associated with fear of falling among community-based seniors using home care services. Age Ageing 2004;33:273-279.

Fritz SL, Pittman AL, Robinson AC, Orton SC, Rivers ED. An intense intervention for improving gait, balance, and mobility for individuals with chronic stroke: a pilot study. J Neurol Phys Ther 2007;31:71-76.

Harris JE, Eng JJ, Marigold DS, Tokuno CD, Louis CL. Relationship of balance and mobility to fall incidence in people with chronic stroke. Phys Ther 2005;85:150-158.

Hess RJ, Brach JS, Piva SR, VanSwearingen JM. Walking skill can be assessed in older adults: validity of the Figure-of- 8 Walk Test. Phys Ther 2010;90:89-99.

Levin MF, Hui-Chan CW. Relief of hemiparetic spasticity by TENS is associated with improvement in reflex and voluntary motor functions. Electroencephalogr Clin Neurophysiol 1992;85:131-142.

Lindquist AR, Prado CL, Barros RM, Mattioli R, da Costa PH, Salvini TF. Gait training combining partial body-weight support, a treadmill, and functional electrical stimulation: effects on poststroke gait. Phys Ther 2007;87:1144-1154.

Lord SE, McPherson K, McNaughton HK, Rochester L, Weatherall M. Community ambulation after stroke: how important and obtainable is it and what measures appear predictive? Arch Phys Med Rehabil 2004;85:234-239.

Lord SE, Rochester L. Measurement of community ambulation after stroke: current status and future developments. Stroke 2005;36:1457-1461.

Perry J, Garrett M, Gronley JK, Mulroy SJ. Classification of walking handicap in the stroke population. Stroke 1995;26:982-989.

Pohl M, Mehrholz J, Ritschel C, Rückriem S. Speed-dependent treadmill training in ambulatory hemiparetic stroke patients: a randomized controlled trial. Stroke 2002;33:553-558.

Salbach NM, Mayo NE, Wood-Dauphinee S, Hanley JA, Richards CL, Côté R. A task-orientated intervention enhances walking distance and speed in the first year post stroke: a randomized controlled trial. Clin Rehabil 2004;18:509-519.

Schmid AA, Van Puymbroeck M, Altenburger PA, Dierks TA, Miller KK, Damush TM, Williams LS. Balance and balance self-efficacy are associated with activity and participation after stroke: a cross-sectional study in people with chronic stroke. Arch Phys Med Rehabil 2012;93: 1101-1107.

Shumway-Cook A, Patla AE, Stewart A, Ferrucci L, Ciol MA, Guralnik JM. Environmental demands associated with community mobility in older adults with and without mobility disabilities. Phys Ther 2002;82: 
670-681.

Stuart M, Benvenuti F, Macko R, Taviani A, Segenni L, Mayer F, Sorkin JD, Stanhope SJ, Macellari V, Weinrich M. Community-based adaptive physical activity program for chronic stroke: feasibility, safety, and efficacy of the Empoli model. Neurorehabil Neural Repair 2009;23:726734. 